\title{
Cloud droplet number enhanced by co-condensation of organic vapours
}

\author{
David Topping, Paul Connolly and Gordon McFiggans *
}

Clouds profoundly influence weather and climate'. The brightness $^{2}$ and lifetime ${ }^{3,4}$ of clouds is determined by cloud droplet number concentration, in turn dictated by the number of available seed particles. The formation of cloud droplets on non-volatile atmospheric particles is well understood ${ }^{5}$. However, fine particulate matter in the atmosphere ranges widely in volatility ${ }^{6,7}$. Co-condensation of semi-volatile compounds with water increases a particle's propensity for cloud droplet formation ${ }^{8}$, with potential consequences for feedbacks between the terrestrial biosphere and climate? Here we systematically study cloud droplet formation, using a cloud parcel model extended to include co-condensation of semi-volatile organic compounds under a broad variety of realistic conditions. As an air parcel rises and cools, the concentration of organic vapour that it can hold declines. Thus, the simulated organic vapours become increasingly saturated as they ascend, and so condense on growing particles as they swell into cloud droplets. We show that condensation of increasingly volatile material adds to the soluble mass of these droplets and facilitates the uptake of additional water, which leads, in turn, to a substantial increase in the number of viable cloud droplets. We suggest that the co-condensation of semi-volatile organic compounds with water vapour has a substantial impact on the radiative properties of clouds.

Size of particles has a greater influence on cloud droplet number concentration $\left(N_{\mathrm{d}}\right)$ than any other intrinsic property of the ambient atmospheric distribution (such as composition, morphology, surface tension lowering and mixing state $\left.e^{5,10,11}\right)$. Most seeds for cloud droplets, cloud condensation nuclei $(\mathrm{CCN})$, are submicrometre complex mixtures of inorganic and organic components of both anthropogenic and biogenic origin. In predicting CCN behaviour, composition and size are implicitly assumed independent and uncoupled, because traditional Köhler theory was specifically derived for particles comprising a single involatile solute and water ${ }^{12}$. However, the organic fraction of atmospheric aerosol comprises many compounds of varying volatility.

Figure la depicts a particle lifted in a cooling air parcel containing both water vapour (represented in blue) and other semi-volatile vapours (green), encountering increased relative humidity and growing into a cloud droplet. Each semi-volatile compound (including water) tends to simultaneously condense from the vapour phase towards particles according to its prevailing saturation ratio (for water, this is the relative humidity), changing particle mass, size and chemical characteristics. As water vapour is most abundant and readily approaches saturation under atmospheric temperatures, condensation of liquid water contributes most to growth, solutes in the particles becoming rapidly diluted. Depletion of water vapour partial pressure by particle growth under subsaturated conditions cannot compensate for decreasing water saturation vapour pressure on cooling and the parcel becomes supersaturated with respect to water. The much sparser semi-volatile vapours are depleted rapidly by condensation under water subsaturated conditions. Dilution by increasing liquid water reduces each component's vapour pressure above the droplet and material continues to condense. Above water saturation, each CCN approaches activation becoming a cloud droplet beyond its critical supersaturation, subsequently exhibiting runaway growth until the growing droplets deplete water vapour and a dynamic steady state is established. Competition for water vapour prevents all potential CCN becoming droplets; some later-activating droplets deactivate and shrink as water vapour is depleted. In cloud, droplets are extremely dilute aqueous solutions, organic equilibrium saturation ratios become vanishingly small (far below ambient saturation ratios) and semi-volatile material continues to condense until almost completely scavenged.

We previously demonstrated ${ }^{8}$ that organic components of ranging volatilities ${ }^{13}$ may depress critical supersaturation of single particles so they activate into cloud droplets more readily than in the absence of organic material. Co-equilibration of products from a near-explicit volatile organic compound (VOC) oxidation model similarly depressed critical supersaturation ${ }^{8}$. Other aerosol properties increasing CCN concentration, $N_{\mathrm{CCN}}$, (for example, surface tension reduction) are damped in their ability to increase $N_{\mathrm{d}}$ when droplets compete for available water vapour ${ }^{5,10}$. In contrast, here we transcend single-particle equilibrium predictions ${ }^{8}$ to show that co-condensation of semivolatile organic molecules substantially affects not only $N_{\mathrm{CCN}}$, but also $N_{\mathrm{d}}$ under realistic conditions, even considering supersaturation depletion by competition for water vapour.

Figure 1b illustrates simulated growth of a population of 300 aerosol particles $\mathrm{cm}^{-3}$ with median diameter $150 \mathrm{~nm}$, s.d. $(\sigma)$ 1.7 , comprising $80 \%$ organic dry mass and $20 \%$ ammonium sulphate, as the moist air containing them rises adiabatically with a reasonable updraught velocity $\left(w=0.3 \mathrm{~ms}^{-1}\right)$ in the presence of a realistic total concentration of organic components of varying volatility in equilibrium with the dry distribution. The blue line shows the relative humidity of the parcel, exhibiting a characteristic peak supersaturation. The red line shows the fractional saturation ratio change of all organic components had they not condensed on growing particles in the ascending air. Green lines show predicted decreases in saturation ratio as semi-volatile organic compounds (SVOCs) condense onto the evolving particle distribution. Saturation ratios decrease by around 3 orders of magnitude, but a cloud droplet's volume can easily be 6 orders of magnitude greater than the particle on which it is formed. 

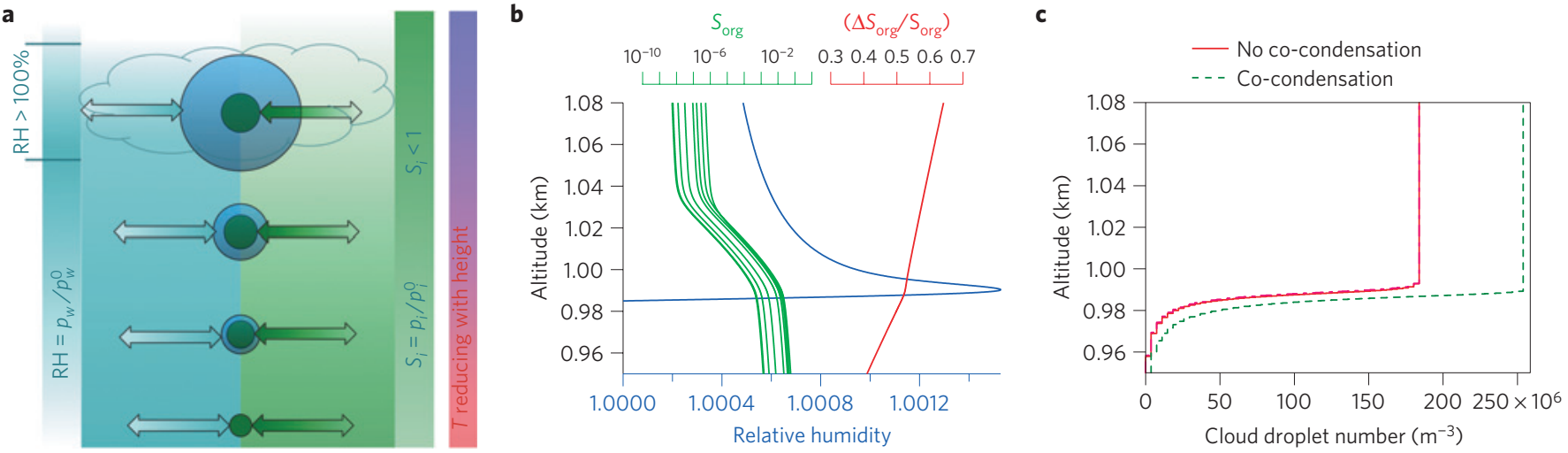

Figure 1 | Cloud formation in the presence of organic vapour. $\mathbf{a}$, Variation in concentration of water (blue area) and organic (green area) material in vapour and condensed phases as an air parcel is lofted. $\mathrm{RH}$, relative humidity. $\mathbf{b}$, Example simulation of relative humidity (blue), saturation ratio of organic vapours after being scavenged by growing droplets (green), and fractional saturation ratio increase with height of organic vapours were they not to condense on growing droplets (red). c, Predicted increase in cloud droplet number $\left(N_{d}\right)$ for the same scenario shown in $\mathbf{b}$ (green dashed line) compared with the assumption of no co-condensation (red line). Simulation conditions are described in the text.

The droplet thereby becomes extremely dilute and the equilibrium vapour pressure of organic components correspondingly reduces. Figure 1c shows the $N_{\mathrm{d}}$ change with semi-volatile condensation. The additional mass condensed on the growing particle population results in a further $40 \%$ becoming cloud droplets. In every simulation, $N_{\mathrm{d}}$ increases above that predicted in the absence of co-condensation, frequently more than in the case illustrated (see Supplementary Figs S2, S4, S5 and S6).

The fraction of material in the growing particle depends both on component volatility and ambient relative humidity. Figure 2 illustrates this for the model run shown in Fig. 1, where the volatility distribution is representative of total organic aerosol (OA; see ref. 13 and Supplementary Section S3 for full explanation of total OA and its constituent fractions, including low-volatility oxygenated OA (LV-OOA) and semi-volatile oxygenated OA (SV-OOA)). Each bar represents the total amount of material in both phases logarithmically binned by volatility, characterized by saturation concentration $\left(C^{*}\right.$, the concentration with $50 \%$ concentration in each phase, micrograms per cubic metre). Components become increasingly volatile towards the right. The yellow part of each bar represents vapour mass under dry conditions; green representing condensed mass. As relative humidity increases, a higher fraction of increasingly volatile material is found in growing droplets, illustrated by the red lines. Condensed mass increases substantially, particularly in higher volatility bins, as relative humidity increases with height (and decreasing temperature). Much more material is therefore present in a particle, with higher average volatility, at cloud base than under drier conditions at the ground or if sampled dry on-board aircraft.

The amount of material condensing during droplet activation is, as expected, dependent on the particle distribution (Supplementary Table S1). Availability of condensable organic vapour is determined by the initial particle size and volatility distributions at equilibrium under dry conditions. Increased constraint by volatilities measured under a wider variety of particle concentrations should be the focus of further work. Sensitivity to the distribution of volatility ${ }^{13}$ is described in the Supplementary Information. Only when using the LV-OOA fraction, is there significant difference from that calculated for total OA because there is, by definition, less higher volatility material available to co-condense with increasing relative humidity. As particles age, oxidation may increase the LV-OOA proportion (also probably increasing higher volatility vapours by fragmentation, offsetting the LV-OOA increase). There is no observational constraint on the extent of SV-versus LV-OOA with age beyond boundary layer timescales, nor on the enhancement of higher volatility material formed by fragmentation. Furthermore,

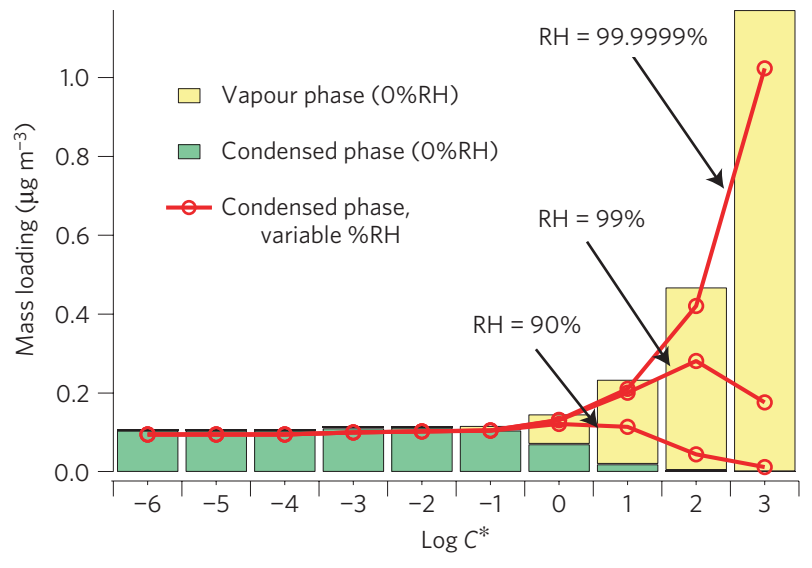

Figure 2 | Volatility distribution of organic components in activating droplets. Predicted by the parcel model simulation illustrated in Fig. 1, the green and yellow bars show the amount of material in the condensed and vapour phases respectively summed across all dry particles according to their volatility $\left(C^{*}\right)$. The red lines show the increase in predicted condensed mass as a function of relative humidity assuming ideality as the air parcel approaches cloud base. $\mathrm{RH}$, relative humidity.

the first cloud pass, closer to the source where there is a lower fraction of LV-OOA, will probably determine the main impact of co-condensation and affect subsequent cloud formation. Such phenomena must be the subject of future work.

A characteristic feature of co-condensation is that the amount of semi-volatile material condensed on each particle reduces with increasing aerosol particle number concentration $\left(N_{\mathrm{a}}\right)$ and vice versa. The ratio of $N_{\mathrm{a}}$ and the amount of semi-volatile material thus determines $N_{\mathrm{d}}$ enhancement. Figure 3 summarizes the dependence of the increase in $N_{\mathrm{d}}$ on $N_{\mathrm{a}}, \sigma$ and updraught velocity, $w$, for particles with $60 \%$ initial dry particle organic mass fraction on an ammonium sulphate core with a semi-volatile distribution representative of Total $\mathrm{OA}^{13}$. Base case model simulations use ideal solution thermodynamics, assuming that the equilibrium vapour pressure of a given component above a droplet of changing composition varies only with solution mole fraction. Should components exhibit low water affinity, their equilibrium vapour pressures above the growing droplet would increase (associated with high activity coefficients). Supplementary Fig. S3 shows that only modest reduction in enhanced condensation with increasing relative humidity is expected. 


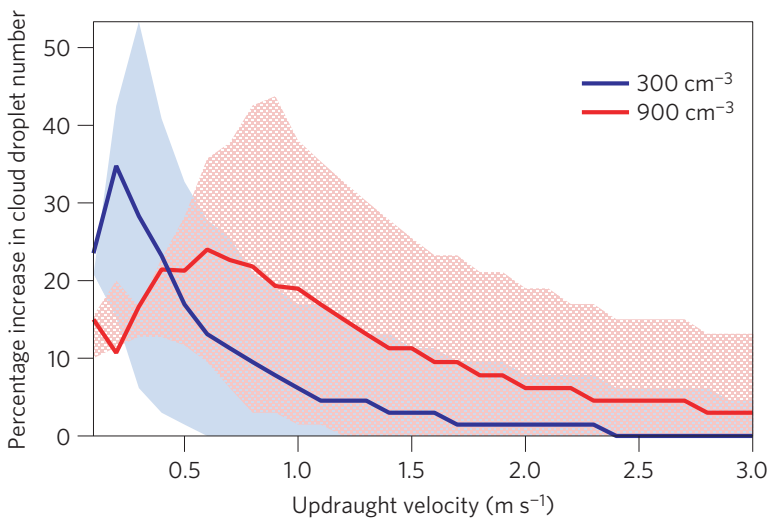

Figure 3 | Increase in droplet number at various updraught speeds. The percentage increase in droplet number $\left(N_{d}\right)$ dependence on particle concentrations $\left(N_{\mathrm{a}}\right)$ of 300 and $900 \mathrm{~cm}^{-3}$, and distribution standard deviation $(\sigma)$, as a function of updraught velocity $(w)$ for particles with a median diameter of $150 \mathrm{~nm}, 60 \%$ dry organic volume fraction and a core of $\left(\mathrm{NH}_{4}\right)_{2} \mathrm{SO}_{4}$. Solid lines represent $\Delta N_{\mathrm{d}}$ for $\sigma$ of 1.7 , the upper and lower bounds of the shaded areas representing $\sigma$ of 1.3 and 2.2, respectively.

Supplementary Figs $S 4$ and S5 show the $N_{\mathrm{d}}$ dependence on dry mass fraction of condensed semi-volatile organic, $\sigma$ and $w . N_{\mathrm{d}}$ enhancement is frequently several tens of per cent across a wide range of conditions. Co-condensation impacts are greater when dry particle organic mass fraction is higher (particles are initially less $\mathrm{CCN}$ active than those comprising hygroscopic $\left(\mathrm{NH}_{4}\right)_{2} \mathrm{SO}_{4}$ and increasing mass makes a greater proportional change in $\left.N_{\mathrm{CCN}}\right)$ and with less hygroscopic cores (Supplementary Fig. S6). An optimum updraught velocity exists at which the co-condensation impact is a maximum. This increases with $N_{\mathrm{a}}$, such that the effect is greatest at $<0.2 \mathrm{~m} \mathrm{~s}^{-1}$ for low particle concentrations $\left(N_{\mathrm{a}}=300 \mathrm{~cm}^{-3}\right)$, corresponding to say, stratocumulus clouds in the remote marine or pristine forest environment, through to around $1 \mathrm{~ms}^{-1}$ at $900 \mathrm{~cm}^{-3}$ (corresponding to say, continental background shallow cumulus).

In summary, three related effects conflate to ensure that semivolatile material influences $N_{\mathrm{d}}$ : saturation ratio of all semi-volatile components (water, other inorganic components and organic components) increases with decreasing temperature; increase in particle mass resulting from condensation of each component increases the potential for condensation of all other components; and increase in liquid water, the condensate dominating growth by virtue of greatest abundance, leads to condensation of greater fractions of increasingly volatile material, both during and after activation. Co-condensation of semi-volatile material and water leads to increases in $N_{\mathrm{d}}$ comparable in magnitude to recently reported model versus measurement biases in droplet closure studies. Compiling measurements screened for adiabaticity from a number of experiments, discrepancies between predicted and measured $N_{\mathrm{d}}$ are brought within measurement uncertainty using reduced condensation coefficients in the comparator parcel model $^{14,15}$. Using a value closer to unity, broadly accepted as that of the water accommodation coefficient ${ }^{16}, N_{\mathrm{d}}$ predictions are biased low. Representing co-condensation may partially or wholly offset this bias. It should be noted that, consistent with recent work investigating growth of particles in organic vapours ${ }^{17}$, we use an accommodation coefficient of unity in our base case simulations for all condensing vapours. Sensitivity to this is discussed in the Supplementary Information and determination of accommodation coefficients of organic semi-volatiles under conditions relevant for droplet activation should be the subject of future research.

An influence on $N_{\mathrm{d}}$ of the magnitude shown will have a substantial impact on the radiative budget and on cloud dynamics. A cooling tendency from a net influence on global albedo ${ }^{18,19}$ of $1.8,0.98$ and $0.51 \mathrm{~W} \mathrm{~m}^{-2}$ can be estimated for $40 \%, 20 \%$ and $10 \%$ enhancement in $N_{\mathrm{d}}$, respectively. For reference, the best estimate of the entire cloud albedo forcing ${ }^{1}$ is about $-0.7 \mathrm{~W} \mathrm{~m}^{-2}$. Impacts will be geographically heterogeneous because of variable surface albedo and variation in VOC sources; nevertheless they are potentially very large. In any case, differences in associated cloud albedo can be estimated as $2.5 \%, 1.4 \%$ and $0.71 \%$, respectively (to within 10\%; ref. 18). The magnitude (and even sign) of the lifetime effects are highly uncertain and very dependent on cloud system scale phenomena ${ }^{4}$, but impacts of $N_{\mathrm{d}}$ changes of several tens of per cent may be substantial. Importantly, SVOCs are formed from atmospheric oxidation of both biogenic and anthropogenic VOCs. Representation of co-condensation of biogenic semi-volatile compounds will help quantify key linkages in a recently postulated feedback mechanism linking emissions from forests through processes involving aerosol to climate ${ }^{9}$. Quantification of impacts of anthropogenically derived semi-volatiles is needed both to investigate man-made perturbations to such feedback mechanisms and to quantify anthropogenic indirect aerosol forcing.

Before this work, only nitric acid and ammonia co-condensation had been investigated, reporting significant enhancement in cloud droplet number ${ }^{20-25}$ and finding variously that condensation of $\mathrm{HNO}_{3}$ broadens the cloud droplet distribution ${ }^{22}$ and that, at low updraught velocities, rain formation is delayed ${ }^{26}$. As we previously found semi-volatile organics to more effectively increase CCN activation behaviour than nitric acid and ammonia ${ }^{8}$, these should be the focus of further studies.

\section{Methods}

The Aerosol-Cloud-Precipitation Interactions Model $^{27}$ was extended to account for the co-condensation of organic material in 10 logarithmically spaced volatility bins as represented elsewhere ${ }^{13}$. The model solves 4 coupled ordinary differential equations for the water vapour mass mixing ratio, $r_{\mathrm{v}}$, pressure, $P$, temperature, $T$, and height, $z$, of an air parcel rising through the moist atmosphere in hydrostatic balance. A further $n+10(1+n)$ coupled equations were included to describe the mass of liquid water in each of the $n$ aerosol size bins; the mass of each of the 10 organic components in each size bin and the vapour mixing ratio each organic (here $n=70$ size bins were found to be sufficient for the simulations). The governing equations for the model are detailed in the Supplementary Information. The model was initialized with 27 different particle size distributions, representing a range from very clean to polluted conditions, each with a range of dry organic mass fraction $(0.2,0.4,0.6$ and 0.8$)$ and three compositions of involatile core. Using measured distributions of volatility of components ${ }^{13}$, the amount of organic vapours available for co-condensation throughout each simulation was calculated from equilibrium with the initial distribution. We conducted 9,720 base case adiabatic cloud parcel model simulations, at 30 different updraught velocities, using the realistic initializations (all detailed in the Supplementary Information), diagnosing the droplet number concentration $\left(N_{\mathrm{d}}\right)$ after the droplet population has stabilized (not at peak supersaturation). In addition, a large number of simulations exploring sensitivity to the distribution of component volatility were conducted (also detailed in the Supplementary Information).

All of the Aerosol-Cloud-Precipitation Interactions Model simulations were run assuming ideal solution thermodynamics. It might be expected that the higher volatility compounds exhibit lower water affinity than those with lower volatility, increasing their equilibrium vapour pressures above the growing droplet. It is impossible to ascribe component activity coefficients solely on the basis of volatility, but the distribution of functionality and molar mass of compounds contributing to the organic vapours in each volatility bin are expected to be reasonably represented by those predicted by a near-explicit model of biogenic and anthropogenic VOC degradation. To test the sensitivity to non-ideality, 2,727 oxidized intermediates predicted from the master chemical mechanism ${ }^{28}$ simulations previously used $^{8}$ were mapped into their volatility bins using vapour pressure estimation from a recently developed technique ${ }^{29}$. Molecular concentrations in each bin were scaled to match the same mass loadings used in the scenario shown in Fig. 2. Activity coefficients were calculated using the UNIFAC (UNIQUAC Functional-group Activity Coefficients) method (ref. 30) method. The sensitivity is presented in the Supplementary Information along with the solubility of components predicted in the growing droplets under assumed ideal and non-ideal conditions.

The impact on the radiative budget of the predicted influence on droplet number is estimated from the change in cloud albedo for a change in droplet number ${ }^{18}: \Delta A_{c}=0.075 \times \ln \left(N / N_{0}\right)$. If the fraction of clouds affected is just that over land (that is, around 0.3 ) and the global cloud fraction is about 0.7 , the change in cloud albedo is related to change in planetary albedo roughly by 
$\Delta A_{\mathrm{p}}=\Delta A_{\mathrm{c}} \times 0.3 \times 0.7$. The solar irradiance $\left(\mathrm{W} \mathrm{m}^{-2}\right)$ is related to planetary albedo $A_{\mathrm{p}}$, by $F=0.25 \times F_{0} \times\left(1-A_{\mathrm{p}}\right)$, where $F_{0}=1370 \mathrm{~W} \mathrm{~m}^{-2}$ and a change in albedo leads to a radiative effect given by $\Delta F=-342.5 \times \Delta A_{\mathrm{p}}$, resulting in the value reported above. The calculation is detailed in the Supplementary Information.

Received 26 September 2012; accepted 28 March 2013; published online 5 May 2013

\section{References}

1. Denman, K. L. et al. in Climate Change 2007: The Physical Science Basis (eds Solomon, S. et al.) (Cambridge Univ. Press, 2007).

2. Twomey, S. The influence of pollution on the shortwave albedo of clouds. J. Atmos. Sci. 34, 1149-1152 (1977).

3. Albrecht, B. A. Aerosols, cloud microphysics and fractional cloudiness. Science 245, 1227-1230 (1989).

4. Stevens, B. \& Feingold, G. Untangling aerosol effects on clouds and precipitation in a buffered system. Nature 461, 607-613 (2009).

5. McFiggans, G. et al. The effect of physical and chemical aerosol properties on warm cloud droplet activation. Atmos. Chem. Phys. 6, 2593-2649 (2006).

6. Jimenez, J. L. et al. Evolution of organic aerosols in the atmosphere. Science 326, 1525-1529 (2009).

7. Hallquist, M. et al. The formation, properties and impact of secondary organic aerosol: Current and emerging issues. Atmos. Chem. Phys. 9, 5155-5235 (2009).

8. Topping, D. \& McFiggans, G. Tight coupling of particle size, number and composition in atmospheric cloud droplet activation. Atmos. Chem. Phys. 12, 3253-3260 (2012).

9. Kulmala, M. et al. A new feedback mechanism linking forests, aerosols, and climate. Atmos. Chem. Phys. 4, 557-562 (2004).

10. Feingold, G. Modeling of the first indirect effect: Analysis of measurement requirements. Geophys. Res. Lett. 30, 1997 (2003).

11. Dusek, et al. Size matters more than chemistry for cloud-nucleating ability of aerosol particles. Science 312, 1375-1378 (2006).

12. Köhler, $\mathrm{H}$. The nucleus in and the growth of hygroscopic droplets. Trans. Farady Soc. 32, 1152-1161 (1936).

13. Cappa, C. D. \& Jimenez, J. L. Quantitative estimates of the volatility of ambient organic aerosol. Atmos. Chem. Phys. 10, 5409-5424 (2010).

14. Conant, W. C. et al. Aerosol-cloud drop concentration closure in warm cumulus. J. Geophys. Res. 109, D13204 (2004).

15. Fountoukis, C. et al. Aerosol-cloud drop concentration closure for clouds sampled during the International Consortium for Atmospheric Research on Transport and Transformation 2004 campaign. J. Geophys. Res. 112, D10S30 (2007)

16. Kolb, C. E. et al. An overview of current issues in the uptake of atmospheric trace gases by aerosols and clouds. Atmos. Chem. Phys. 10, 10561-10605 (2010).

17. Riipinen, I. et al. The contribution of organics to atmospheric nanoparticle growth. Nature Geosci. 5, 453-458 (2012).

18. Schwartz, S. E. \& Slingo, A. in Clouds, Chemistry, and Climate (eds Crutzen, P. \& Ramanathan, V.) 191-236 (Springer, 1996).

19. Wang, J., Lee, Y-N., Daum, P. H., Jayne, J. \& Alexander, M. L. Effects of aerosol organics on cloud condensation nucleus $(\mathrm{CCN})$ concentration and first indirect aerosol effect. Atmos. Chem. Phys. 8, 6325-6339 (2008).
20. Kulmala, M. et al. The effect of atmospheric nitric-acid vapor on cloud condensation nucleus activation. J. Geophys. Res. 98, 22949-22958 (1993).

21. Laaksonen, A., Hienola, J., Kulmala, M. \& Arnold, F. Super- cooled cirrus cloud formation modified by nitric acid pollution of the upper troposphere. Geophys. Res. Lett. 24, 3009-3012 (1997).

22. Hegg, D. A. Impact of gas-phase $\mathrm{HNO}_{3}$ and $\mathrm{NH}_{3}$ on microphysical processes in atmospheric clouds. Geophys. Res. Lett. 27, 2201-2204 (2000).

23. Kokkola, H., Romakkaniemi, S. \& Laaksonen, A. Kohler theory for a polydisperse droplet population in the presence of a soluble trace gas, and an application to stratospheric STS droplet growth. Atmos. Chem. Phys. 3, 2139-2146 (2003)

24. Xue, H. W. \& Feingold, G. A modeling study of the effect of nitric acid on cloud properties. J. Geophys. Res. 109, D18204 (2004).

25. Romakkaniemi, S., Kokkola, H. \& Laaksonen, A. Parameterization of the nitric acid effect on CCN activation. Atmos. Chem. Phys. 5, 879-885 (2005).

26. Roelofs, G.-J. \& Jongen, S. A model study of the influence of aerosol size and chemical properties on precipitation formation in warm clouds. J. Geophys. Res. 109, D22201 (2004)

27. Connolly, P. J., Emersic, C. \& Field, P. R. A laboratory investigation into the aggregation efficiency of small ice crystals. Atmos. Chem. Phys. 12, 2055-2076 (2012)

28. Jenkin, M. E., Saunders, S. M. \& Pilling, M. J. The tropospheric degradation of volatile organic compounds: A protocol for mechanism development. Atmos. Environ. 31, 81-104 (1997).

29. Nannoolal, Y., Rarey, J. \& Ramjugernath, D. Estimation of pure component properties. Part 3. Estimation of the vapour pressure of non-electrolyte organic compounds via group contributions and group interactions. Fluid Phase Equilibr. 269, 117-133 (2008).

30. Fredenslund, A., Jones, R. L. \& Prausnitz, J. M. Group-contribution estimation of activity coefficients in nonideal liquid mixtures. AIChE J. 21, 1086-1099 (1975).

\section{Acknowledgements}

All authors would like to acknowledge financial support from the UK Natural Environment Research Council under the 'Aerosol-Cloud Interactions-a Directed Programme to Reduce Uncertainty in Forcing (ACID-PRUF)' grant, NE/IO20121/1. D.T. acknowledges financial support from the National Centre for Atmospheric Science.

\section{Author contributions}

G.M. conceived the study; D.T. and P.C. developed the model code. D.T, P.C. and G.M. designed the simulations; D.T. and P.C. carried out the data analysis; G.M., P.C. and D.T. co-wrote the paper.

\section{Additional information}

Supplementary information is available in the online version of the paper. Reprints and permissions information is available online at www.nature.com/reprints. Correspondence and requests for materials should be addressed to G.M

\section{Competing financial interests}

The authors declare no competing financial interests. 